\title{
Telecommunication Externality on Migration: Evidence from Chinese Villages ${ }^{1}$
}

\author{
Yi Lu \\ National University of Singapore \\ Huihua Xie \\ National University of Singapore \\ Lixin Colin $\mathrm{Xu}$ \\ World Bank
}

August 25, 2014

\begin{abstract}
We use a unique data set of Chinese villages to investigate whether access to telecommunications, in particular, landline phones, increases the likelihood of outmigration. By using regional and time variations in the installation of landline phones, our difference-in-differences (DID) estimation shows that the access to landline phones increases the ratio of out-migrant workers by 2 percentage points, or about 51 percent of the sample mean in China. The results remain robust to a battery of validity checks. Furthermore, landline phones affect outmigration through two channels: information access on job opportunities and timely contact with left-behind family members. Our findings underscore the positive migration externality of expanding telecommunications access in rural areas, especially in places where migration potential is large.
\end{abstract}

Keywords: Landline phones; telecommunications; migration; network effect; psychological costs; China.

\footnotetext{
${ }^{1}$ The views expressed here are the authors' own and do not implicate the World Bank, the countries that it represents, and its executive directors.
} 


\section{Introduction}

The past decades have witnessed a surge in intranational migration. In the past three decades in China, 500 million people have flocked to the city, and during 2000-2010 alone, China's urban population expanded by 210 million (Wong 2012; World Bank and DRC, 2014). Outmigration is generally found to profoundly contribute to the welfare of both the recipient and sending destinations. Beegle, De Weerdt and Dercon (2008), for instance, find that migration between 1991 and 2004 increase consumption growth rate in Tanzania by 36 percentage points. Despite the significant economic benefits, however, there are still substantial barriers to labor mobility. Why do so many potential migrants fail to act out their wishes? How can we increase the likelihood of outmigration?

The literature on the determinants of migration, starting from the classical Harris and Todaro (1970), emphasizes the rural-urban earning differentials as the key reason. Moreover, scholars recognize that a fundamental problem in migration is uncertainty. Potential migrants do not have full information about job opportunities, wages, and the quality of life in destination cities, and new evidence on migrants' expectations in developing countries suggest how inaccurate these expectations can be (McKenzie, Gibson and Stillman 2013). The literature has recognized and provided evidences that an important way to reduce information problems is through the channel of networks (Barr and Oduro 2002; Hanson and McIntosh 2010; Kilic and others 2009; McKenzie and Rapoport 2010; Munshi 2003; Uhlig 2006; Winters, de Janvry, and Sadoulet 2001; Yamauchi and Tanabe 2008). The literature also suggests that fast-changing information technology and its associated exposure on urban life would change the quality of information received by potential migrants and, therefore, their migration decisions. For instance, individuals exposed to foreign media and social media are more likely to migrate (Braga 2009; Komito 2011). Access to mobile phones increases the probability and intensity of rural-urban migration by offering more information 
about the labor market at the destination (Aker, Clemens, and Ksoll 2011; Muto and Yamano2009). ${ }^{2}$ Moreover, the impact of mobile phone coverage expansion on migration depends on personal networks: the expansion of a mobile phone network strengthens the effect of the existing ethnic network on migration (Muto and Yamano2009; 2011). But better information does not uniformly encourage migration-it depends on whether potential migrants over- or under-estimate the prospects of the potential destinations. If potential migrants over-estimate their employment and life prospects in the destination region, better access to information may decrease migration, as found by Farre and Fasani (2012).

In this paper, we investigate whether the availability of information technology, in particular, the access to in landline phones, can loosen the constraints on potential migrants and lead to an increase in outmigration. How does telecommunications access affect outmigration? We consider two potential reasons. First, telecom technologies allow potential migrants to access external labor market information, which substantially reduces their searching costs and increases the accuracy of their costs-benefits analysis of migration decisions. Second, telecom access allows migrants convenient and timely contacts with their left-behind family members, which substantially reduces the psychological costs of migration. This is especially important in China because of the prevailing policies regarding access to education and health care those discriminate against migrants, which results in adults largely leaving their families and migrating alone (Wong 2012; World Bank and DRC, 2014).

Using the data of the National Fixed Point Survey conducted by the Ministry of Agriculture of China in 1993 and 1995-2000, we exploit regional and time variations in the installation of landline phones to identify the causal effect of landline phones on outmigration. Out of 61 villages in our sample, 35 had landline phones in 1993 (i.e., our initial year), 23 installed landline phones at different times during the sample period, and 3 remained without

\footnotetext{
${ }^{2}$ For studies looking at how mobile phones reduce market information asymmetry in general, see Jensen (2007), Aker (2010), etc.
} 
access to landline phones by 2000 . Meanwhile, other telecom technologies, such as mobile phones and the Internet, only started to penetrate in the late 1990s and mostly in rich and coastal cities. Hence, our research setting allows us to separate the effect of landline phones from other competing telecom technologies. Furthermore, our identification is aided by directly controlling for the exposure to other information sources, such as newspapers and televisions. An important advantage of relying on landline phones to identify the effects of telecom technology is that we face a less serious challenge of endogeneity. Individuals can purchase mobile phones, and the access to mobile phones is closely related to personal ability, wealth, and demand for modern technology, which may be strongly related to the migration decision. In contrast, the installation of landline phones at the village level, as we document later, was largely related to several easily observable variables, and thus, its endogeneity for migration can be more easily dealt with. Perhaps because of this reason, our estimates of the telecom effects on migration are quite stable.

Based on the difference-in-difference (DID) approach, we find that the installation of landline phones leads to an increase in the ratio of out-province migrant workers in total rural labor force by 1.5-2 percentage points, or 38.5-51 percent of the sample mean. The results are robust to a battery of validity checks, such as using DID coupled with matching, controlling for pretreatment effect, and using a flexible estimation method to account for differences in the time trend in outmigration of treatment and control groups. Two placebo tests also confirm our identification assumptions. First, if the telecom effect merely reflects the time trend in relatively rich villages, then villages always with telecom access should have higher migration trends, but we find a similar trend in the migration levels for villages always with telecom access and those never with telecom access. Second, if the telecom effects on outmigration reflect effects other than the information or timely contact with left-behind 
families (as we hypothesize), telecom access will likely affect out-village, within-county migration, but we do not find that telecom access affects such short-distance migration.

We further test our two proposed mechanisms through which landline phones may increase outmigration, that is, information access and timely contact with left-behind family members. We find that the positive effect of landline phones on outmigration is greater for villages with a larger pool of previous out-migrants (a proxy for the information access through the network effect) and for villages with more young children (a proxy for left-behind family members).

Our paper is complementary to the existing literature on the determinants of migration in several ways. First, by using unique data on landline phone installation and by taking advantage of the predictive nature of landline phone installation at the village level, we have a relatively transparent and plausible strategy for identifying the effects of telecom on migration. The robustness of the results under a variety of specification checks testifies the plausibility of our identification strategy. Second, our evidence comes from the country that has experienced the largest migration in the world during which migration was in full swing (World Bank and DRC, 2014), and it is useful to know whether modern telecom would have quantitatively important impact on migration. We find it is so. Third, there is little evidence of how family structure and psychological costs of migration affect migration, and in this paper, our results suggest that modern telecom may reduce the psychological costs of migration by allowing migrants to stay in touch with their children left behind in the villages.

The paper is organized as follows. In Section 2, we describe the rural-to-urban migration and the development of landline phones in China. In Section 3, we describe the data and key variables. Section 4 presents the empirical strategy. Section 5 shows our empirical findings. Section 6 concludes. 


\section{Background}

\subsection{Rural-to-Urban Migration in China}

Because of food shortage and the great famine after the collapse of the Great Leap Forward in the early 1960s, the Chinese government started to restrict inter-region migration, especially rural-to-urban migration, to ensure that sufficient resources stayed in agriculture production and to contain pressure for job creation in the cities. Specifically, the government adopted a household registration system (hukou in Chinese), which delineates where a person can live and what social welfare programs he or she is entitled to (e.g., Wu 1994; Zhao 2000). Without an urban residence permit (urban hukou), a farmer could not live and work in the city. It became nearly impossible for farmers to obtain urban hukou after the early 1960s (Naughton 2007). From 1949 to 1985, the average rural-to-urban migration rate for China was only 0.24 , compared with a world average of 1.84 from 1950 to 1990 (Zhao 2000).

Since 1978, China has embarked on a great economic and social transformation, which has subsequently led to substantial changes in the rural-urban divide. In rural China, the household responsibility system emerged and eventually replaced the previous commune system, which greatly improved agricultural efficiency and generated surplus labor (Lin 1992; Zhao 2004). In urban areas, the development of a market-oriented economy, the establishment of special economic zones, the expansion of the non-state sector, and the loosening of the urban employment policy created strong demand for migrant labor (Cai 2001; Meng and Zhang 2001). In addition, decades of rural-urban segregation and uneven economic growth led to a large income gap between urban and rural areas, which provided a stimulus for people to migrate to coastal and eastern China (Bao and others 2011). All these developments have contributed to China's surge in internal rural-to-urban migration.

According to the National Bureau of Statistics of China, rural out-migrant workers are defined as individuals who have rural household registration status but left their homeland 
and have worked outside the towns and counties for at least 6 months. As shown in Figure 1, the number of rural out-migrant workers rose from around 20 million in 1990 to 62 million in 1993, 132 million in 2000, and nearly 160 million in $2011 .^{3}$ Most of these migrant workers, constrained by their lower education levels, work in the manufacturing and construction sectors in cities. However, rural-to-urban migration has significantly benefited both recipient and sending areas. For example, the Pearl Delta and Yangtze River Delta regions have emerged as one of the most important global manufacturing bases since the 1990s, partly because of the constant supply of cheap rural labor (Huang and Zhan 2005). And the large amount of remittances has greatly contributed to the economic development of inland rural areas through both consumption and investment and has helped reduce rural poverty since the late 1990s (de Brauw and Rozelle 2008).

\section{[Insert Figure 1 Here]}

Unlike migrations in many other countries, rural-to-urban migration in China has its own features. Because of the presence of the household registration system, rural migrants find it difficult to permanently settle down in recipient cities for a long time. ${ }^{4}$ Also, they are largely denied access to many of the social welfare programs, such as education and medicine, to which their urban counterparts are entitled. Indeed, typically, migrant workers on average return home two to three times annually and spend less than 9 months in recipient cities (Zhao 1999). Another important feature of rural-to-urban migration in China is the emergence of the village-based migrant network. Because of decades of separation, rural households have limited ties with urban communities and little access to institutional supports at the destinations, making them rely on their origin-based networks to find jobs (e.g., Solinger 1999; Zhao2003). This is also common in many other developing countries (Barr and

\footnotetext{
${ }^{3}$ Some other estimates are greater. For instance, Wong (2012) suggests that China's urban population expanded by 210 million.

${ }^{4}$ This issue has changed substantially in the past few years. It has become easier for migrants to settle down in small cities, though the access to vital social services remains disadvantaged for migrants relative to residents with local urban hukou.
} 
Oduro 2002; Munshi 2003; Uhlig 2006; Winters, de Janvry, and Sadoulet 2001; Yamauchi and Tanabe 2008). Meng(2000) shows that 70 percent of rural-to-urban migrants in China found their jobs through village-based friends or relatives. Before the arrival of modern telecommunications technologies, such as landline and mobile phones, potential migrants largely had to wait for temporary returns of previous migrants (such as during the Spring Festival) to obtain labor market information in cities, which generated substantial delays and high search costs. ${ }^{5}$

\subsection{Development of Landline Phones in China}

When the People's Republic of China was established in 1949, the country had only 300,000 telephones, or 0.05 sets per 100 people. In addition, telecom facilities were largely outdated and concentrated in just a few large cities, such as Chongqing, Shanghai, and Wuhan (Wauschkuhn, 2001).From 1949 to China's economic reform initiated in 1978, the government gave priority to developing heavy industry and largely neglected investment in telecommunications. As a result, the number of telephones grew very slowly relative to the growth in population: the tele-density in 1978 was only 0.38 sets per 100 people (see Figure 1).

In the late 1980s, economic reforms led to rapid growth in the economy. The booming economy started to call for better communications services, the shortage of which clearly became a key bottleneck for further development. Thus, in the seventh five-year plan in 1985, the State Council, or the cabinet, stated that telecom development would become a national priority and the focus was to develop telecom facilities in major cities and coastal areas. Meanwhile, the government allowed telecom companies to borrow from state-owned banks and foreign sources and to enjoy preferential tax rates. As a result, the number of landline

\footnotetext{
${ }^{5}$ Another way to obtain information is through mail system, which took days and weeks depending on the location and delivery convenience. However, rural migrants tend not to be prolific letter writers.
} 
phones started to rise, growing at an average annual rate of 17 percent between 1986 and 1990 (Clegg, Kamall, and Leung 1996). However, the incentive schemes and federal support systems were only given to specific areas (i.e., 14 open coastal cities and 5 special economic zones), which amplified the telecom advantage of the key cities against the rural areas. By 1991, these specific areas accounted for nearly 25 percent of telecom networks in China (Wu 2008), and almost all subscribers were living in urban areas while people in remote rural parts of China remained unconnected.

For a long time before the late 1990s, the Ministry of Posts and Telecommunications was the regulator and main operator of telecom services, and telecom monopoly seriously constrained the development of the industry. In the late 1990s, partly following the worldwide trend ( $\mathrm{Li}$ and $\mathrm{Xu} 2004)$, China started telecom deregulation and liberalization by granting more administrative autonomy to the Post and Telecommunications Bureaus at the regional and local levels, by introducing more competitors to market, and by gradually opening the telecom markets to foreign investors. As a result, service quality has dramatically improved and tariffs have fallen substantially, leading to a record growth in landline phone subscribers. ${ }^{6}$ As shown in Figure 1, the number of landline phones per 100 people increased from less than 1 in 1990 to more than 12 in 2000, and the number continued to rise to 28.1 by 2006. Meanwhile, with the introduction of new technologies, other telecom modes, such as cellular phones and the Internet, began to penetrate China. For example, the number of cellular phone users surpassed the number of landline phone users in 2003 and peaked at 75 sets per 100 people by 2011. The number of Internet users has increased nearly 7 times between 2002 and 2011. However, between 1993 and 2000 (our sample period), landline phones were the primary telecom tool, especially in rural areas. The exclusive reliance on landline phones in the rural areas thus allows us to focus on a single telecom technology.

\footnotetext{
${ }^{6}$ Using cross-country data, $\mathrm{Li}$ and $\mathrm{Xu}$ (2004) find that both telecom privatization and competition facilitated telecom development, especially when both are done at the same time.
} 
Moreover, because the introduction of a landline phone network was largely determined by village characteristics, as we will demonstrate later, we should be able to identify the effects more convincingly than to identify the telecom effects of mobile phones, which involves individual- or household-level selectivity to a larger extent.

\section{Data and Variables}

The data come from the National Fixed Point Survey conducted by the Ministry of Agriculture of China in 1986-1991, 1993, and 1995-2000. ${ }^{7}$ Because surveys in 1986-1991 do not contain information on landline phones, we restrict our analysis to the 1993 and 1995-2000 surveys. The survey sites were randomly sampled from six provinces (i.e., Gansu, Guangdong, Hubei, Liaoning, Shandong, and Yunnan provinces). The sample provinces are spread out across China, ranging from coastal to inland areas and covering northern, southern, western and eastern China; they also feature diverse levels of economic development, climate, natural endowment, and infrastructure.

We have a total of 67 villages in 1993. Six villages were deleted because they changed location codes over time, for which we cannot trace. Among the remaining 61 villages, 35 villages had landline phones in 1993; 23 villages installed landline phones during the sample period; and 3 villages had no landline phones installed even at the end of our sample period.

The key variables for our analysis are the measure of out-province migrant workers as our dependent variable, and an indicator of installation of landline phones as a regressor of interest. In National Fixed Point Survey, labors or workers is defined as males with ages between 16 and 60 and females between ages 16 and 55. In the survey, a labor is classified as the migrant worker if the individual has worked outside the village (including out-village and

\footnotetext{
${ }^{7}$ Surveys were not conducted in 1992 and 1994 because of financial reasons.
} 
within-county, out-county and within-province, out-province and within-China, and overseas) for most of the time of a year. ${ }^{8}$ Table 2 reports the summary statistics of our key variables. During the sample period (1993, 1995-2000), the overall ratio of out-province migrant workers to total labor force is 3.9 percent, and the overall ratio of out-village, within-county migrant workers is 5.2 percent. Meanwhile, our sample villages are quite poor with an average annual income per capita of 2076 yuan or US\$333, small (i.e., 479 households living in a7-square-kilometer area), and mostly located out of the mountains (i.e., 68 percent).

\section{[Insert Table 1 Here]}

Note that the distances among 61sample villages are quite large, averaging 835 kilometers between any two villages. Such long distances make the spillover effect of landline phones from the treatment group to the control group quite unlikely. ${ }^{9}$

We present summary statistics of landline phone accessibility in Table 3. The number of villages with landline phones in our data increased from 35 in 1993 to 58 in 2000 (panel A). Except for Gansu province, all villages in the other provinces in our data had access to landline phones by the end of 2000 (panel B). Finally, the timing of installing landline phones varies across our sample villages and time (panel C). For example, most landline phones in Hubei province were installed in the early years of our sample period (i.e., 1993, 1995-1996), while installation occurred much late in Gansu province (i.e., 1998-2000). Such variations afford us a good opportunity to identify the causal effect of landline phones by using the difference-in-difference (DID) estimation method.

[Insert Table 2 Here]

\footnotetext{
${ }^{8}$ In China, the administrative hierarchy in the rural areas is central government, followed by provincial government, municipal government, county government, and then village government. There are 32 provinces, 345 municipalities, 2,856 counties, and 4,044,907 villages in April 2013.

${ }^{9}$ It is possible that non-sampled villages in between might also be treated, and there might be spillover effects from non-sampled treatment villages to our control villages. In this case, our estimation gives us the lower bound of the land-line phone effects.
} 


\section{Empirical Strategy}

We rely on the DID approach to identify the causal effect of access to landline phones on outmigration. Our baseline estimation equation is as follows:

$$
y_{v t}=\alpha_{v}+\gamma_{t}+\beta \text { Tele }_{v t}+\varepsilon_{v t},
$$

where $y_{v t}$ is the ratio of out-province migrant workers to the total labor force in village $v$ at year $t$. Tele ${ }_{v t}$ is equal to 1 if village $v$ had landline phones at year $t$ and 0 if not. $\alpha_{v}$ is the village fixed effect, capturing all time-invariant village heterogeneity, such as the distance away from coastal regions, culture, village inequality, and so on. $\gamma_{t}$ is the year fixed effect, capturing all yearly shocks common to all villages, such as the business cycle, macro level regulations, and the trend in income growth. $\varepsilon_{v t}$ is the error term. To deal with the potential heteroskedasticity and serial correlation, we cluster the standard error at the village level to avoid overstating estimation precision (Bertrand, Duflo, and Mullainathan, 2004).

Note that in our data, there are three types of villages: (1) some had landline phones through the whole sample period (referred to as incumbents); (2) some had no landline phones through the whole sample period (referred to as outsiders); and (3) some installed landline phones during the sample period at different time points (referred to as switchers). The staggered nature of landline installation provides us with useful identifying variations. In the baseline DID estimation, we first use the whole sample and hence our DID identification essentially comes from a comparison of the early installing switchers with the later installing switchers, incumbents and outsiders. Second, we focus on the switchers that are assumed to be more homogeneous, and the identification relies on the comparison of the early installing switchers with the later installing ones. Note that there are only 23 villages in this robustness check analysis. Hence, to adjust the inference issue of few clusters, we use the Wild cluster-bootstrap percentile-t procedure developed by Cameron, Gelbach, Miller (2008). As a 
further robustness checks, we take advantage of the fact that there is no status change in the incumbents and outsiders--the comparison between these two groups provides us with a good placebo test, i.e., for two comparison groups without treatment, their differences in the outcome should be stable over time. The identifying assumption associated with the DID estimation equation (4) is that, conditional on the controls, our regressor of interest (i.e., the interaction between the treatment status indicator and post-treatment period indicator) is uncorrelated with the error term. That is,

$$
E\left[\varepsilon_{v t} \mid \text { Tele }_{v t}, \alpha_{v}, \gamma_{t}\right]=E\left[\varepsilon_{v t} \mid \alpha_{v}, \gamma_{t}\right]
$$

In the remaining part of this section, we discuss potential violations of our identifying assumption and our remedies, as well as several robustness checks.

\subsection{Placement and Timing of Landline Phone Installation}

A potential challenge to the DID estimation specification is that the place and timing of the installation of landline phones are not random. For example, more remote and poorer villages could install landline phones later than coastal and richer villages. One may then be concerned that such preexisting differences across treatment and control groups may explain the post-treatment divergence in the ratio of out-migrant workers, causing a spurious correlation between our explanatory variable of interest and the outcome variable. Thus, one must understand what determines which village installed landline phones earlier to isolate the effect of landline phones on outmigration.

To this end, we first conducted an intensive online research on how China Telecom Corporation, the monopoly of telecommunications in the 1990s and early 2000s, decided which village to be connected to the landline phone network first in the 1990s. ${ }^{10}$

\footnotetext{
${ }^{10}$ The search engine we used is Baidu, the Chinese version of Google and the best in searching Chinese websites.
} 
Unfortunately, there is not much discussion online about the determinants of landline phone connection. Among the sporadic pieces of information we found, most websites cite income level as the main reason. We then interviewed one China Telecom Corporation employee to get first-hand information about landline phone installation. We were told that when choosing which village was connected to the landline phone network first, the company mainly considered the degree of facility use, which is closely related to village's level of economic development.

We next conduct a regression analysis on the determinants of landline phone connection based on the aforementioned anecdotal evidences. Specifically, we first consider the village's level of economic development, that is, average income per capita and total population. We then consider special government policies, that is, whether the village was officially classified as a poverty village and whether it was officially classified as a disadvantaged village ${ }^{11}$ — both categories of villages are supposed to enjoy compensatory treatment over many policies. We also consider geographic features (that may affect the costs of installing landline phones), that is, the percentage of arable land, whether the village was in the mountainous area, the distance to the nearest county or municipal (or prefecture) government, and the distance to the main road. Lastly, we investigate whether the installation was triggered by the needs of out-migrant workers, and thus consider both the existing and potential out-migrant workers. We use the ratio of out-county migrant workers in 1991 to measure the existing out-migrant workers, and use percentage of idle labors as a proxy for potential migrant workers, use the percentage of remittance income and the percentage of loan earnings as proxies for financial constraints of migration. All these determinant variables were measured in the pretreatment stage in 1991.

\footnotetext{
${ }^{11}$ Disadvantaged areas are regions that are occupied with vulnerable groups and minorities and tend to be far away from economic centers.
} 
The regressions results are reported in Table 1. Columns [1] to [4] deal with the placement of landline phones, and the dependent variable is whether a village installed landline phones in 1993. Columns [5] to [8] concern the timing of the installation, and the dependent variable is the number of years from the initial year (i.e., 1993) of the sample until the year that the village installed landline phones. We also experimented with the Cox proportional hazards model; the qualitative results are similar. ${ }^{12}$

\section{[Insert Table 3 Here]}

The findings are consistent with our anecdotal evidence about the key importance of local income level. Indeed, richer villages are more likely to have landline phones in 1993 (columns [1] to [4]) and more likely to install landline phones earlier (columns [5] to [8]). Average income per capita and total population together can explain around 23-30 percent of the total variations in the placement and timing of landline phone installation. Meanwhile, villages that were classified as "poor villages" or "disadvantaged villages" and were closer to the nearest county or municipal (or prefecture) government were more likely to have landline phones in 1993 and more likely to install landline phones earlier, while villages located in mountainous areas were less likely to have landline phones in 1993 and more likely to install landline phones later. None of the remaining determinants are statistically significant. In particular, the ratio of out-migrant workers in 1991 and proxies for potential migrant workers are consistently insignificant, suggesting that the installation of landline phones is not reversely caused by our outcome variable.

In summary, our evidences in this subsection, both qualitatively and quantitatively, show that the average income of a village, the population in a village, the "poor village" status, the "disadvantaged village" status, the distance to the nearest county or municipal (or prefecture) government, and the topographic conditions are important factors in determining

\footnotetext{
${ }^{12}$ The results are available upon request.
} 
whether the village installed landline phones and its timing. Meanwhile, conditional on these key determinants, other factors are found to be not statistically significant, especially the pretreatment ratio of outmigration villagers. Although 54 percent of the differences between treatment and control groups remain unexplained, we are unable to locate other factors that significantly drive both the selection of landline phone installation and the post-installation differential in migration between these two groups.

\subsection{Augmented Estimation Specification and Robustness Checks}

We have established that the treatment and control groups ex ante differ significantly in village's level of economic development. To alleviate the concern that pre-existing differences in economic development between the treatment and control groups may generate the differential patterns of outmigration over time, we follow Gentzkow (2006) in controlling for a flexible time trend in outmigration generated by the preexisting village characteristics. Specifically, we interact a second-order polynomial function of time with the village's average income per capita in 1991, total population (in logarithm form) in 1991, the "poor village" status in 1991, the "disadvantaged village" status in 1991, the indicator of being in mountainous area, and the distance to the nearest county or municipal (or prefecture) government. ${ }^{13}$ Moreover, we also control for some other village characteristics and the exposure of other media which may affect out-migration, including the number of firms, percentage of non-labor force, sex ratio, the number of newspapers and magazines subscribed per household, and the number of TV sets per households. However, worrying that these control variables may be affected by the installation of landline phones, we use the values of these controls in 1993 and interact them with the second-order polynomial function of time.

\footnotetext{
${ }^{13} \mathrm{We}$ also use the distance to the nearest county or municipal government as a proxy to control for other infrastructure (such as roads/trains) and commuting time--migrant workers live closer to county or municipal government will be more easily able to travel between work and home location. Moreover, using fourth-order polynomial function of time in the interactions generates very similar results.
} 
Nonetheless, using interactions with forth-order polynomial function of time or the time-varying values of these control variables generate similar results. ${ }^{14}$

Hence, our augmented DID estimation specification becomes

$$
y_{v t}=\alpha_{v}+\gamma_{t}+\beta \text { Tele }_{v t}+\mathbf{X}_{v t}{ }^{\prime} \eta+\varepsilon_{v t},
$$

where $\mathbf{X}_{v t}$ is a vector of additional controls discussed earlier. The new identifying assumption is

$$
E\left[\varepsilon_{v t} \mid \text { Tele }_{v t}, \mathbf{X}_{v t}, \alpha_{v}, \gamma_{t}\right]=E\left[\varepsilon_{v t} \mid \mathbf{X}_{v t}, \alpha_{v}, \gamma_{t}\right]
$$

\section{Empirical findings}

\subsection{Main Results}

Figure 2 shows the difference in the ratio of out-migrant workers between treatment and control groups over time. Clearly, the treatment and control groups have similar ratios of out-migrant workers 2 years and 1 year before the installation of landline phones in treatment villages. Right after the installation of landline phones, treatment villages experience an increase in the ratio of out-migrant workers, and the trend continues for at least 2 more years.

Regression results using the DID specification (i.e., equation [6]) are reported in Table 4. We start with including only year and village fixed effects in column [1] of the upper panel. Here, landline phones have a positive and statistically significant coefficient, which is consistent with the findings in Figure 2. This result suggests that access to landline phones increases the ratio of outmigration by 2 percentage points.

[Insert Figure 2 Here]

[Insert Table 4 Here]

In columns [2]-[3], we progressively add second-order time polynomial function of time interacted with village characteristics in 1991/1993 to control for the possible

\footnotetext{
14 The results are available upon request.
} 
differences among villages. Village characteristics include average income per capita in 1991, total population (in logarithm form) in 1991, the "poor village" status in 1991, the "disadvantaged village" status in 1991, the indicator of being in mountains area, the distance to the nearest county or municipal (or prefecture) government, the number of firms in 1993, the percentage of non-labor force in 1993, the sex ratio in 1993, the number of newspapers and magazines subscribed per household in 1993, and the number of TV sets per households in 1993. Evidently, our estimated coefficients of landline phones not only remain statistically significant but also have the same magnitude - the landline phone effect on migration ratio is 2 percentage points, or about 51 percent of the mean (i.e., 3.9 percent).

While in the lower panel of Table 4, we focus on the switchers group (those villages installed landline phones during our sample period), which are presumably more homogenous. To address the issue of a small number of clusters, we calculate the standard errors using the Wild cluster-bootstrap percentile-t procedure developed by Cameron, Gelbach, and Miller (2008). The installation of landline phones is still found to positively and statistically significantly affect the out-migration, with a slightly decline in the magnitude. The landline phone effect on migration ratio is 1.5 percentage points, or about 38.5 percent of the sample mean.

\subsection{Robustness Checks}

In Table 5, we conduct several robustness checks on our identifying assumption (equation [7]).

[Insert Table 5 Here]

One potential challenge to our DID estimation is that even with a long list of controls (i.e., village dummies, various time-varying village characteristics, and so on), there may remain some unobserved time-varying village characteristics that drive both the installation 
of landline phones and changes in the ratio of out-migrant workers. Such local characteristics would include local government officials' attitude toward outmigration, variation in hukou access across villages in rural China, or the village's evolving policies on land reallocation when local residents migrate. Although such variables are likely to change gradually over time rather than suddenly or all at once, their effects are likely to appear as if changes in outmigration would anticipate the installation of landline phones (Jensen and Oster 2009). This is similar to the preprogram test in labor economics (Heckman and Hotz 1989), and the significance of the "landline phone anticipator" likely indicates that the landline phone effect merely reflects the influence of related confounding factors. To check the possibility of such confounding effects, we include an indicator for installing landline phones next year in the regression. As shown in column [1] of Table 5, the "effect" of installing landline phones next year is statistically insignificant, and our main coefficient remains robust to this control, supporting the validity of our DID estimation. ${ }^{15}$

Second, we use a more flexible specification for installing landline phones in the future and past, that is, replacing our regressor of interest $\left(\right.$ Tele $\left._{v t}\right)$ with a series of time dummies indicating various distance in time to the landline installation year (the default time category is at least three years before the installation).Such an exercise can shed light on whether the treatment and control groups are comparable until the time of treatment and become different after that time. As shown in column [2] of Table 5, we find similar patterns in outmigration between treatment and control groups before the installation of landline phones, but they diverge right after the installation. Furthermore, we test whether the post-installation coefficients are different from pre-installation ones, the $\mathrm{F}$ statistic for the joint test is 2.74 , and we can reject the null hypothesis that all the post-treatment coefficients

\footnotetext{
15 As a rough but important additional test, we also exclude "Tele" in the same regression, and find that "landline phone anticipator" still remains statistically insignificant (the results are available upon request).
} 
are equal to the pre-treatment coefficients at 5 percent level, and thus further support our argument.

\subsection{Two Placebo Tests}

We now conduct two placebo tests to offer further support to our key results. First, in the survey, we have three villages that had not installed landline phones by the end of the sample period (i.e., 2000). If outmigration is truly triggered by landline phones, we should see a similar trend in the ratio of out-migrant workers between villages with landline phones and those without landline phones throughout the entire sample period, because their landline phone status did not change over time. In other words, for two comparison groups without treatment, their differences in the outcome should be stable over time. Indeed, Figure 3shows that the differences between the two comparison groups, despite some fluctuations, remain similar over our sample period.

\section{[Insert Figure 3 Here]}

Second, in our theory, the effect of landline phones on outmigration originates from the sharing of job information and timely contact with left-behind family members. Because villages within the same county are quite close, these two roles of landline phones may not be important, and we should expect that landline phones have no impact on migration to different villages or towns within the same county. To test this implication, we construct a new outcome variable, With-county, which is the percentage of out-village, within-county migrant workers (in total village labor force), and we re-estimate equation (6) using this outcome variable (see column [3] of Table 5). Evidently, there is no statistically significant effect of landline phones on out-village, within-county migration.

\subsection{Using DID Matching}


To ensure that our results are not driven by functional form assumptions, we use an alternative estimation method. That is, we use the propensity score matching method to locate an ex ante similar control village for each of our treatment villages, and we then conduct a DID estimation based on these matched data. Specifically, matching is conducted based on the average income per capita, total population, whether being classified as "disadvantaged village", whether being in mountainous area, the distance to the nearest county or municipal (or prefecture) government, the number of firms in the village, the percentage of non-labor force, the sex ratio in the village, the number of newspapers and magazines subscribed per household, and number of TV sets per households from the initial year of the sample until the village installed landline phones. For the treatment villages that installed landline phones in each sample year between 1995 and 2000, we conduct one-to-one propensity score matching to locate a similar control village from a group of villages that had landline phones before that year. As shown in column [4] of Table 5, we find similar results for the landline phone effect using this matched sample.

\subsection{Mechanism}

We now check for two mechanisms through which landline phones affects outmigration, that is, the provision of information on outside job opportunities and timely contact with left-behind family members. For the first channel to work, we expect the effect of landline phones to be stronger for villages having a larger stock of pretreatment out-migrant workers (a proxy for the information access through the network effect). For the second channel to work, we expect the effect of landline phones to be stronger for villages having a larger number of young children (a proxy for left-behind family members).

Regression results are reported in Table 6. In column [1], we add the interaction term between landline phone and ratio of out-province migrant workers in previous year. The 
coefficient of the interaction term is positive and significant, suggesting that the effects of landline phones on the ratio of out-migrant workers are larger for villages with more previous out-migrant workers. In column [2] of Table 6, we add the interaction of landline phone and the percentage of children aged 7 to 13 . Consistent with our argument, we find that the effects of landline phones on the ratio of out-migrant workers are larger for villages with more young children. In column [3], we include both interactions in the same regression and conduct a "horse race" between the two channels in order to access the relative strength of each channel. As shown in the table, a one standard deviation increase in the ratio of previous out-migrant workers would lead to a 0.39 standard deviation increase in the effect of landline phones on out-province migration ratio; and increasing the ratio of children in the previous year by one standard deviation would boost the effect of landline phones on out-province migration ratio by 0.11 standard deviation. Thus, the results render strong support to our conjectures that landline phone availability facilitates migration by reducing information costs on job searches and lessening psychological costs of leaving families behind. It appears that the strength of the information-cost channel is relatively larger.

[Insert Table 6 Here]

\section{Conclusion}

Using a unique natural experiment in which the installation of landline phones in a village was easily explained by obvious village factors with the added advantage of no other telecommunications options available to confound our analysis, we rely on the DID approach to identify the effect of access to landline phones on outmigration. We find that the effect is substantial, increasing the probability of outmigration by roughly 51 percent (or 2 percentage points). The results are robust to alternative controls and an alternative estimation approach. Our various specification checks, such as placebo tests, pretreatment tests, and so on, also 
render support to our identifying assumptions based on the DID approach. Perhaps more convincingly, we find that the landline phone effects are achieved mainly through two channels: by reducing job search costs (as we find the effect is stronger when the village had a large migrant network in the pretreatment period) and by timely contacting left-behind families (as we find the effect to be stronger in villages with more children).

Our paper implies that modern communication technology has a large role to play in facilitating labor mobility between rural and urban sectors, and thus adds to recent literature that provides empirical evidence on the critical importance of modern telecom on economic development. ${ }^{16}$ Since labor movement from low- to high-productivity sectors is a primary avenue for economic growth (e.g., Ngai and Pissarides 2007; Robinson 1971), the government should take into account the positive externality of having modern telecom technology installed in rural areas. Such externality is unlikely to be taken into account when telecom is monopolized by specific ministries, as in the case of China-in this case the ministry is likely to consider only the economic benefits of installing additional landline phones (or mobile towers) for the ministry or the telecom operators. Indeed, in our specification checks, we find that the decision to install a landline phone network only depended on local income level, but not the previous migrant network. Because our findings suggest that the benefits of a telecom network would be higher in areas with a larger migrant network and more children, it is perhaps important for telecom providers to internalize the extra benefits for providing telecommunications in such villages.

\footnotetext{
${ }^{16}$ Harrison, Lin and $\mathrm{Xu}$ (forthcoming) provide evidence that modern telecom is of key importance for explaining cross-country firm-level performance around the world, and African countries' disadvantage in this area partly explains their firm performance disadvantage.
} 
Figure 1: Time Trends of Migrant Workers and Development of Telecom in China

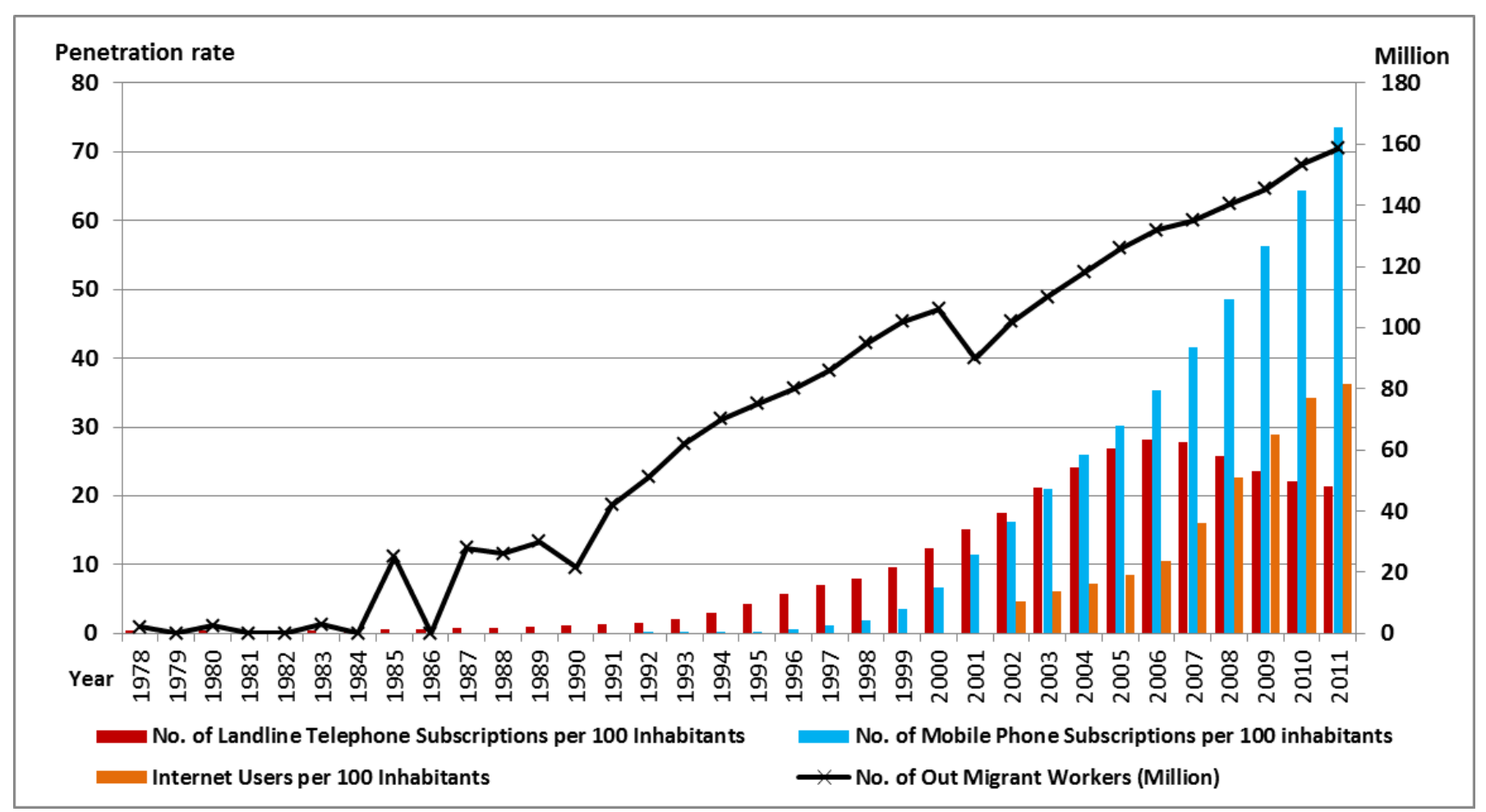

Sources: Second National Agricultural Census Key Data Bulletin (2008); Survey Monitoring Report of China's Migrant Workers (2011); and Contemporary Chinese Migrant Workers Flow Scale Expedition (2010) conducted by the National Bauru of Statistics of China. 
Figure 2: Differences in Ratio of Out-Migrant Workers between Treatment and Control Groups over Time

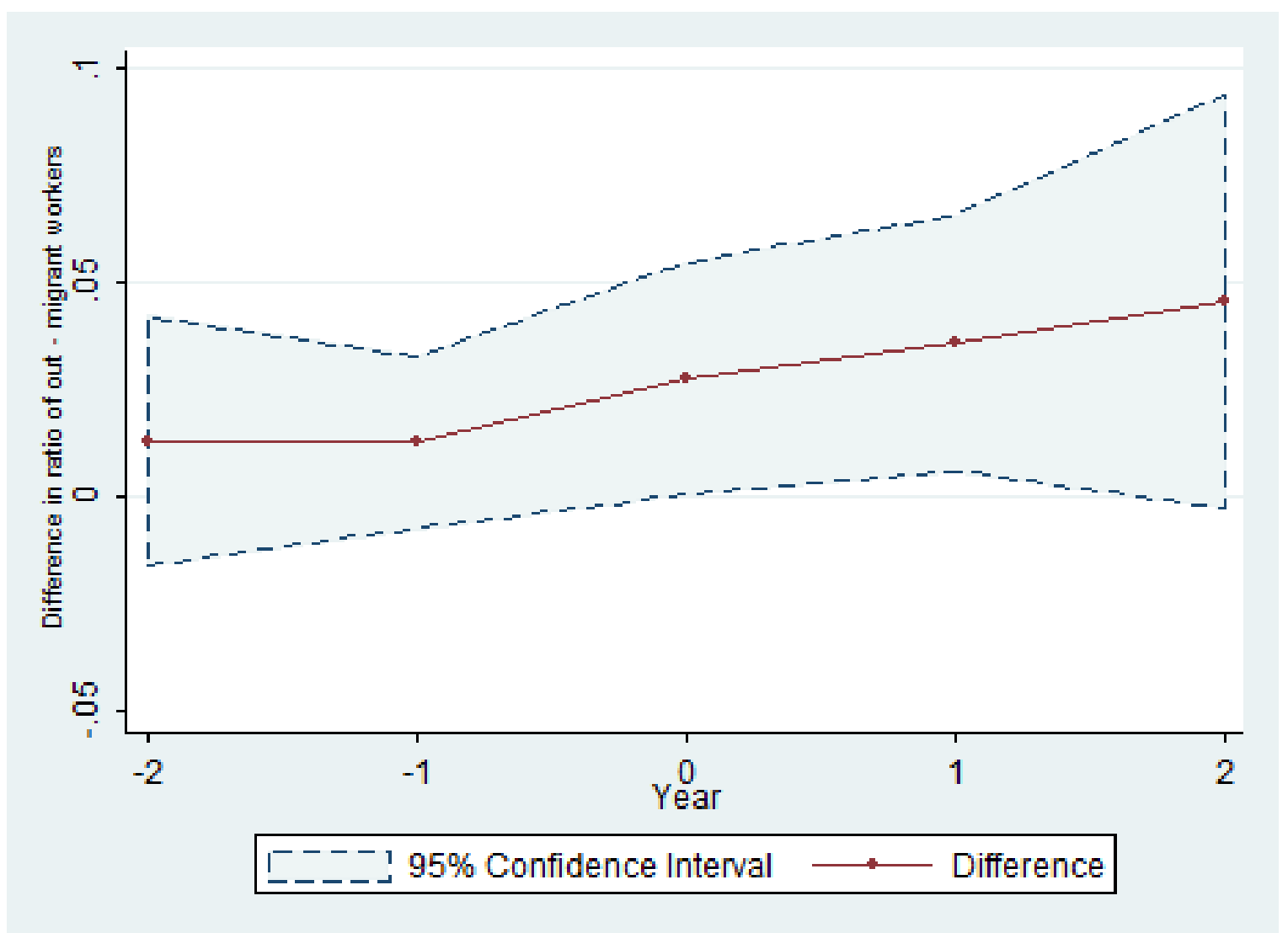

Note. The time in the x-axis represents the distance (in years) to the year of landline installation. 
Figure 3: Differences Between Villages with Landline phones and those without throughout the Whole Sample Period

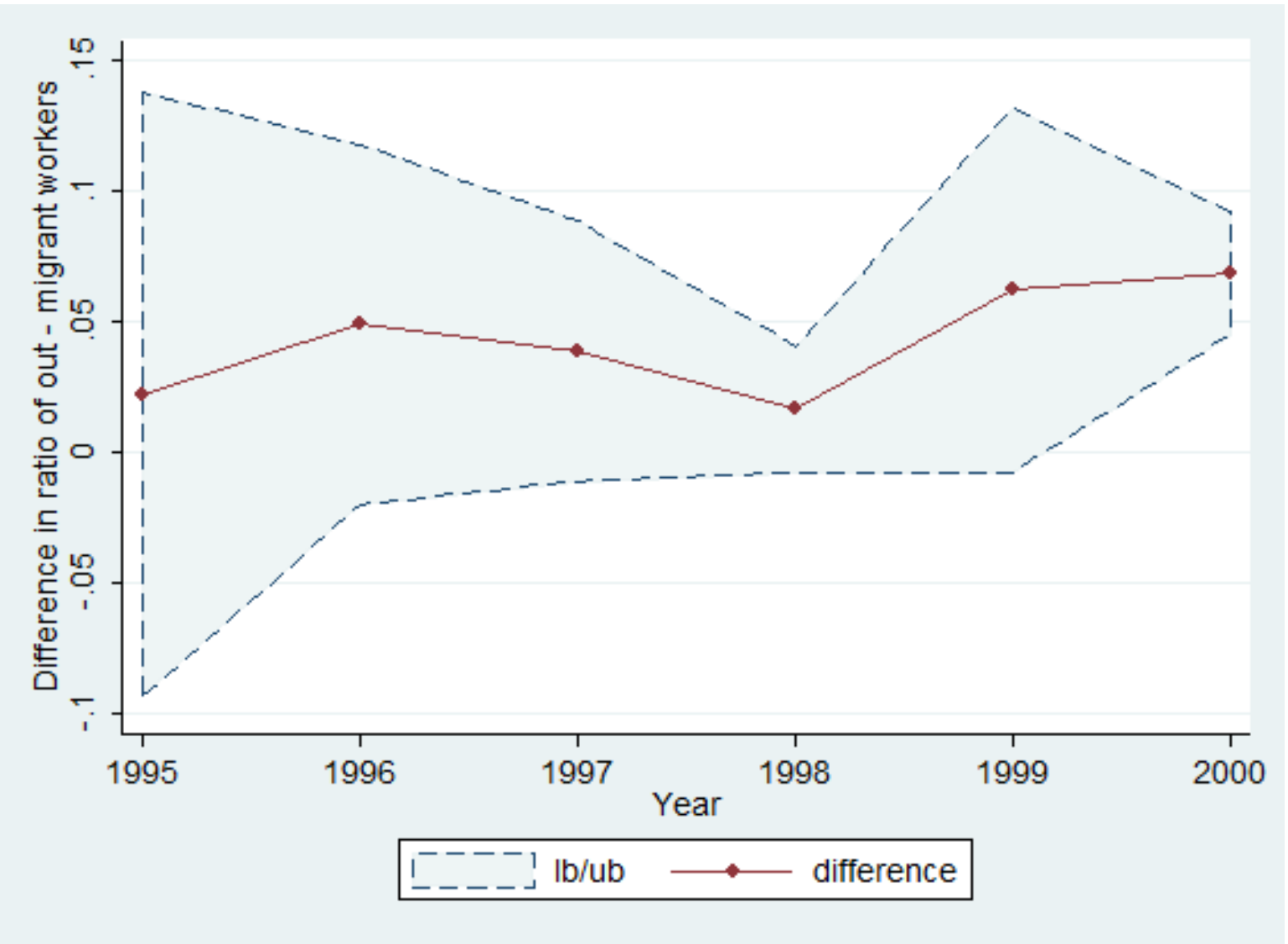


Table 1: Summary Statistics

\begin{tabular}{|c|c|c|c|}
\hline & Mean & S.D. & \# Obs \\
\hline \multicolumn{4}{|c|}{ A. Proportion of migrant workers in total rural labor force } \\
\hline Out-province & 0.039 & 0.066 & 422 \\
\hline Out-village, within-county & 0.052 & 0.073 & 422 \\
\hline \multicolumn{4}{|c|}{ B. Village characteristics } \\
\hline Average income per capita (Yuan) & 2075.910 & 1353.469 & 422 \\
\hline No. of households & 479.401 & 356.767 & 422 \\
\hline Arable land area/total land area & 0.516 & 0.333 & 422 \\
\hline Proportion of villages located in mountain areas & 0.318 & 0.466 & 422 \\
\hline Proportion of villages classified as "Poor Village" & 0.104 & 0.306 & 422 \\
\hline Proportion of villages classified as in " Disadvantaged Areas" in 1991 & 0.305 & 0.464 & 59 \\
\hline No. of newspapers per household & 0.230 & 0.263 & 422 \\
\hline No. of TV sets per household & 0.808 & 0.235 & 422 \\
\hline Distance to the main road & 1.775 & 2.739 & 422 \\
\hline Distance between every two villages & 834.530 & 464.830 & 3721 \\
\hline
\end{tabular}


Table 2: Summary Statistics on Landline phone Availability

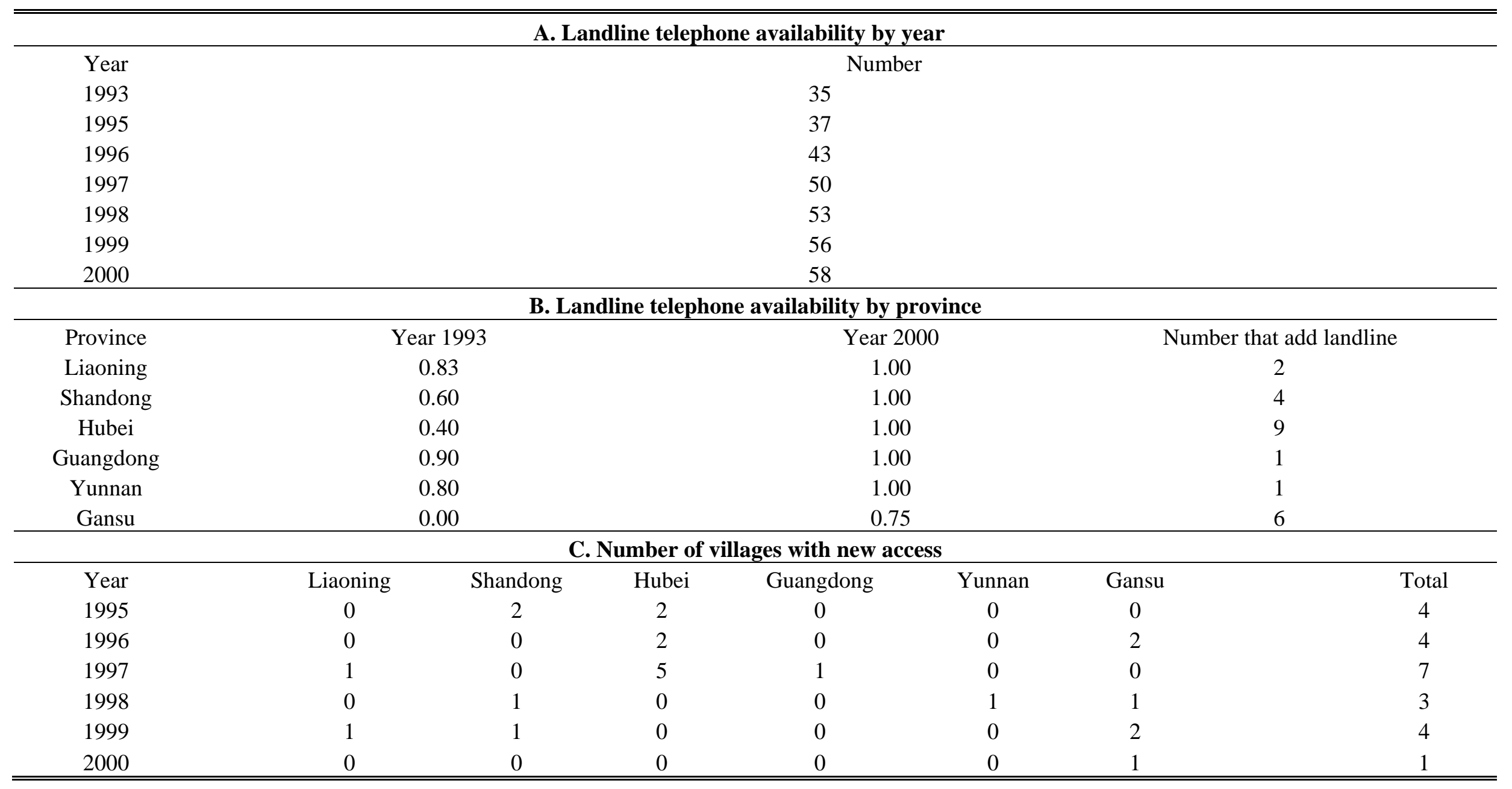


Table 3: Place and Timing of Landline phone Installation

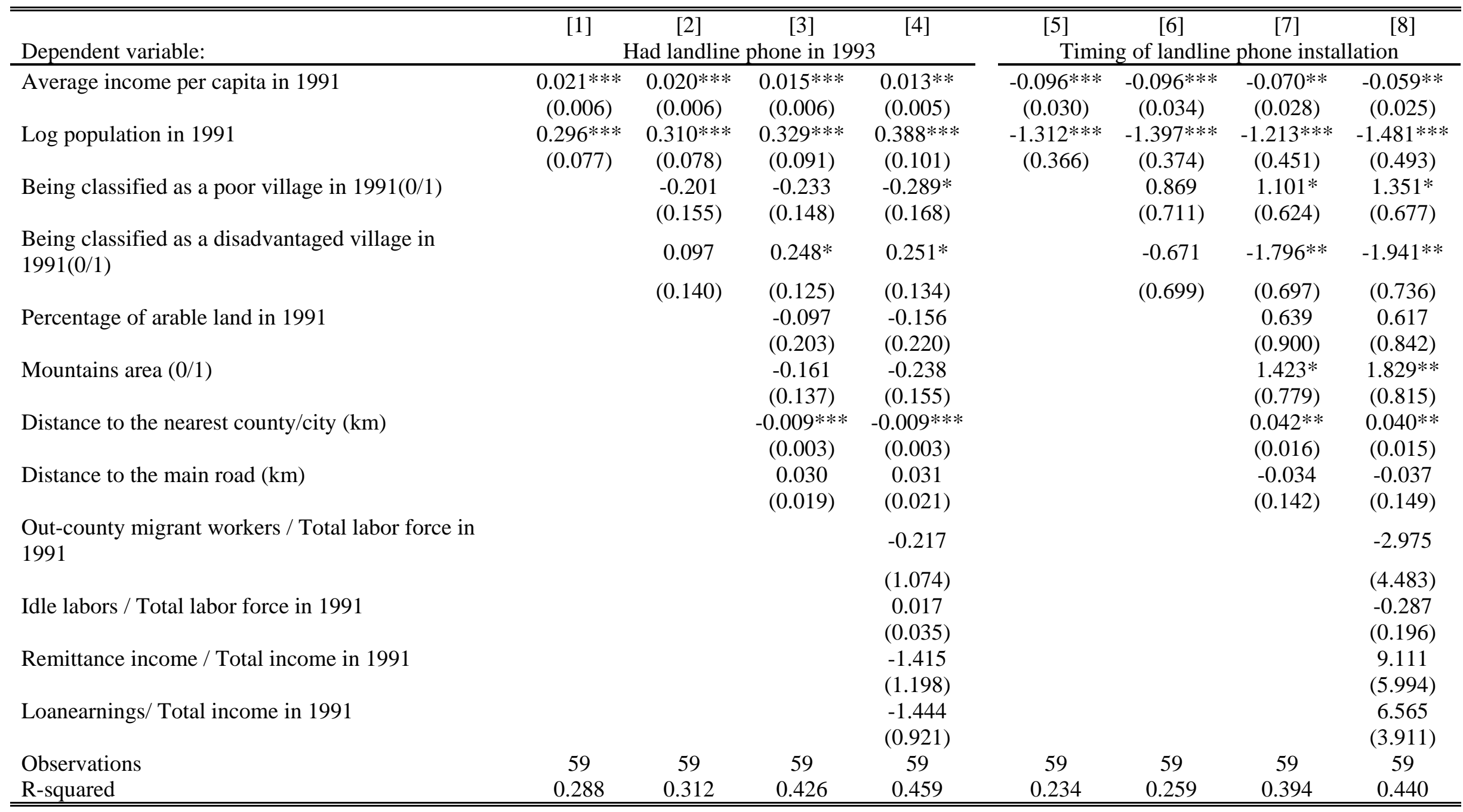

Note: Standard errors in parentheses are clustered at village level. $* * * \mathrm{p}<0.01, * * \mathrm{p}<0.05, * \mathrm{p}<0.1$ 
Table 4: Baseline Results

\begin{tabular}{lccc}
\hline \hline Dependent variable & {$[1]$} & {$[2]$} & {$[3]$} \\
Regressors: & Ratio of out-province migrant workers \\
\hline Panel A: Full Sample & & & \\
Tele & $0.020^{* *}$ & $0.020^{* *}$ & $0.020^{* *}$ \\
& $(0.008)$ & $(0.008)$ & $(0.008)$ \\
Year fixed effect & $\mathrm{Y}$ & $\mathrm{Y}$ & $\mathrm{Y}$ \\
Village fixed effect & $\mathrm{Y}$ & $\mathrm{Y}$ & $\mathrm{Y}$ \\
Time polynomial interactions with: & & & \\
Determinant variables in 1991 & $\mathrm{N}$ & $\mathrm{Y}$ & $\mathrm{Y}$ \\
Control variables in 1993 & $\mathrm{N}$ & $\mathrm{N}$ & $\mathrm{Y}$ \\
Observations & 422 & 411 & 411 \\
R-squared & 0.067 & 0.152 & 0.168 \\
Number of villages & 61 & 59 & 59 \\
& & & \\
Panel B: Sample of Switchers & & & $0.015^{* * *}$ \\
Tele & 0.014 & $0.016^{* * *}$ & $(0.000)$ \\
& $(0.009)$ & $(0.000)$ & $\mathrm{Y}$ \\
Year fixed effect & $\mathrm{Y}$ & $\mathrm{Y}$ & $\mathrm{Y}$ \\
Village fixed effect & $\mathrm{Y}$ & $\mathrm{Y}$ & $\mathrm{Y}$ \\
Time polynomial interactions with: & & & $\mathrm{Y}$ \\
Determinant variables in 1991 & $\mathrm{N}$ & $\mathrm{Y}$ & 160 \\
Control variables in 1993 & $\mathrm{N}$ & $\mathrm{N}$ & 0.850 \\
Observations & 160 & 160 & 23 \\
R-squared & 0.775 & 0.836 & 23 \\
Number of villages & 23 & & \\
\hline \hline
\end{tabular}

Notes: 1. Determinant variables in 1991 include average income per capita, log population, being classified as disadvantaged areas, being classified as poor village, distance to the nearest county or municipal (or prefecture) government, being in mountains areas;

2. Other control variables in 1993 include sex ratio, ratio of non-labor force, no. of firms in the village, newspaper per household, and TV sets per household;

3. In the upper panel, standard errors in parentheses are clustered at the village level; whereas in the lower panel, standard errors in parentheses are calculated using the Wild cluster-bootstrap percentile-t procedure developed by Cameron, Gelbach, and Miller (2008). $* * * \mathrm{p}<0.01, * * \mathrm{p}<0.05$. 
Table 5: Robustness Checks

\begin{tabular}{|c|c|c|c|c|}
\hline Specification & \multicolumn{2}{|c|}{$\begin{array}{c}\text { Ratio of out-province } \\
\text { migrant workers }\end{array}$} & $\begin{array}{l}\text { Within } \\
\text { county }\end{array}$ & $\begin{array}{c}\text { [4] } \\
\text { Matching }\end{array}$ \\
\hline Tele & $\begin{array}{c}0.023 * * * \\
(0.008)\end{array}$ & & $\begin{array}{c}0.003 \\
(0.010)\end{array}$ & $\begin{array}{l}0.018 * \\
(0.010)\end{array}$ \\
\hline Tele next year & $\begin{array}{l}-0.005 \\
(0.005)\end{array}$ & & & \\
\hline 2 years before installation & & $\begin{array}{c}0.012 \\
(0.015)\end{array}$ & & \\
\hline 1 year before installation & & $\begin{array}{c}0.008 \\
(0.011)\end{array}$ & & \\
\hline time of installation & & $\begin{array}{l}0.024 * \\
(0.014)\end{array}$ & & \\
\hline 1 year after installation & & $\begin{array}{l}.034 * * \\
(0.016)\end{array}$ & & \\
\hline 2 years + after installation & & $\begin{array}{c}0.044 \\
(0.028)\end{array}$ & & \\
\hline Year fixed effect & $\mathrm{Y}$ & $\mathrm{Y}$ & $\mathrm{Y}$ & $\mathrm{Y}$ \\
\hline Village fixed effect & $\mathrm{Y}$ & $\mathrm{Y}$ & $\mathrm{Y}$ & $\mathrm{Y}$ \\
\hline Time polynomial interactions $\mathrm{w}$ & & & & \\
\hline Determinant variables in 1991 & $\mathrm{Y}$ & $\mathrm{Y}$ & $\mathrm{Y}$ & $\mathrm{N}$ \\
\hline Control variables in 1993 & $\mathrm{Y}$ & $\mathrm{Y}$ & $\mathrm{Y}$ & $\mathrm{N}$ \\
\hline $\begin{array}{l}\text { Province time dummies } \\
\text { F test for treatment } \times\{\text { time } 0 \text {, } \\
\text { post } 1 \text {, post } 2+\}\end{array}$ & & $\begin{array}{l}2.74 * * \\
0.038\end{array}$ & & \\
\hline Observations & 411 & 376 & 411 & 170 \\
\hline R-squared & 0.169 & 0.225 & 0.138 & 0.238 \\
\hline Number of villages & 59 & 54 & 59 & 51 \\
\hline
\end{tabular}

Notes:1. Determinant variables in 1991 include average income per capita, log population, being classified as disadvantaged areas, being classified as poor village, distance to the nearest county or municipal (or prefecture) government, being in mountains areas;

2. Other control variables in 1993 include sex ratio, ratio of non-labor force, no. of firms in the village, newspaper per household, and TV sets per household.

3. Standard errors in parentheses are clustered at village level. $* * * \mathrm{p}<0.01, * * \mathrm{p}<0.05$. 
Table 6: Mechanisms

\begin{tabular}{lccc}
\hline \hline & {$[1]$} & {$[2]$} & {$[3]$} \\
Dependent variable & Ratio of out-province migrant & workers \\
\hline Tele & -0.010 & -0.004 & -0.025 \\
& $(0.010)$ & $(0.021)$ & $(0.025)$ \\
Tele $\times$ Ratio of migrant workers in previous year & $0.456^{* *}$ & & $0.459^{* *}$ \\
& $(0.200)$ & & $(0.198)$ \\
migrant workers/ labor force in previous year & $0.380^{*}$ & & $0.382^{*}$ \\
& $(0.224)$ & & $(0.224)$ \\
Tele $\times$ Ratio of children (7-13) in previous year & & 0.086 & 0.119 \\
& & $(0.182)$ & $(0.189)$ \\
children (7-13) / total population in previous year & & -0.048 & -0.155 \\
& & $(0.183)$ & $(0.215)$ \\
Year fixed effect & & & \\
Village fixed effect & $\mathrm{Y}$ & $\mathrm{Y}$ & $\mathrm{Y}$ \\
Time polynomial interactions with: & $\mathrm{Y}$ & $\mathrm{Y}$ & $\mathrm{Y}$ \\
Determinant variables in 1991 & & & \\
Control variables in 1993 & $\mathrm{Y}$ & $\mathrm{Y}$ & $\mathrm{Y}$ \\
Observations & $\mathrm{Y}$ & $\mathrm{Y}$ & $\mathrm{Y}$ \\
R-squared & & & \\
Number of villages & 292 & 292 & 292 \\
\hline \hline
\end{tabular}

Notes:1. Determinant variables in 1991 include average income per capita, log population, being classified as disadvantaged areas, being classified as poor village, distance to the nearest county or municipal (or prefecture) government, being in mountains areas;

2. Other control variables in 1993 include sex ratio, ratio of non-labor force, no. of firms in the village, newspaper per household, and TV sets per household.

3. Standard errors in parentheses are clustered at village level. $* * * \mathrm{p}<0.01, * * \mathrm{p}<0.05$. 


\section{References}

[1] Adams Jr, Richard H., and John Page (2005). Do International Migration and Remittances Reduce Poverty in Developing Countries. World Development 33(1), 1645-1669.

[2] Alan, De Brauw, and Scott Rozelle (2008). Migration and Household Investment in Rural China. China Economic Review 19, 320-335.

[3] Aker, Jenny C., Michael A. Clemens, and Christopher Ksoll (2011). Mobiles and Mobility: the Effect of Mobile Phones on Migration in Niger. Working Paper, http://sites.tufts.edu/jennyaker/research-2/.

[4] Bao, Shuming, Örn B. Bodvarsson, Jack W. Hou, and Yaohui Zhao (2011). The Regulation of Migration in a Transition Economy: China's Hukou System. Contemporary Economic Policy 29(4), 564-579.

[5] Barr, Abigail, and Abena Oduro (2002). Ethnic Fractionalization in an African Labour Market. Journal of Development Economics 68(2), 355-379.

[6] Bertrand, Marianne, Esther Duflo, and Sendhil Mullainathan (2004). How Much Should We Trust Differences-in-Differences Estimates?. Quarterly Journal of Economics 114, $249-275$.

[7] Borjas, George (1987). Self-Selection and the Earnings of Immigrants. American Economic Review 77, 531-553.

[8] Braga, Michela (2007). Dreaming Another Life. The Role of Foreign Media in Migration Decisions: Evidence from Albania. Working Paper, http://microdata.worldbank.org/index.php/citations/135.

[9] Cai, Fang (2001). Institutional Barriers in Two Processes of Rural Labor Migration in China. Working Paper Series No. 9, Institute of Population Studies, Chinese Academy of Social Sciences.

[10]Cameron, A. Colin, Jonah B. Gelbach, and Douglas L. Miller (2008). Bootstrap-Based Improvements for Inference with Clustered Errors. Review of Economics and Statistics 90(3), 414-427. 
[11]Clegg, Jeremy, Syed Kamall, and Mary Leung (1996). European Multinational Activity in Telecommunications Services in the Peoples' Republic of China: Firm Strategy and Government Policy. Management International Review 36, 111-137.

[12]Clemens, Michael A. (2011). Economics and Emigration: Trillion-dollar Bills on the Sidewalk?. The Journal of Economic Perspectives, 83-106.

[13]Duflo, Esther, and Rohini Pande (2007). Dams. Quarterly Journal of Economics 122(2), 601-646.

[14]Deshingkar, Priya, and Sven Grimm (2005). Internal Migration and Development: a Global Perspective. No. 19, United Nations Publications.

[15]Farre, Lidia, and Francesco Fasani (2012). Media Exposure and Internal Migration-Evidence from Indonesia. Journal of Development Economics 102, 48-61.

[16]Gentzkow, Matthew (2006). Television and Voter Turnout. Quarterly Journal of Economics 121, 931-972.

[17]Hanson, Gordon H., and Craig McIntosh (2010). The Great Mexican Emigration. The Review of Economics and Statistics 92(4), 798-810.

[18]Hanson, Gordon (2010). International Migration and the Developing World", in Dani Rodrik and Mark Rosenzweig eds. Handbook of Development Economics, Volume 5, the Netherlands: Elsevier, North-Holland.

[19]Harrison, Ann E., Justin Yifu Lin, Lixin Colin Xu (2014). Explaining Africa's (Dis) advantage. World Development, forthcoming.

[20]Heckman, James J., and V. Joseph Hotz (1989). Choosing among Alternative Nonexperimental Methods for Estimating the Impact of Social Programs: The Case of Manpower Training. Journal of the American Statistical Association, 84 (408), 862-874.

[21]Huang P. and S. Zhan (2005). Internal migration in China: Linking it to development. In Migration, Development and Poverty Reduction in Asia, International Organization for Migration, Geneva.

[22]Jensen, Robert and Emily Oster (2009). The Power of TV: Cable Television and Women's Status in India. Quarterly Journal of Economics 124, 1057-1094. 
[23]Harris, John R., and Michael P. Todaro (1970). Migration, Unemployment and Development: A Two-Sector Analysis. American Economic Review 60, 126-142.

[24]Kilic, Talip, Galogero Carletto, Benjamin Davis, and Alberto Zezza (2009). Investing Back Home Return Migration and Business Ownership in Albania. Economics of Transition 17(3), 587-623.

[25]Klonner, Stefan, and Patrick J. Nolen (2010). Cell Phones and Rural Labor Markets:

Evidence from South Africa. Unpublished, http://econstor.eu/bitstream/10419/39968/1/354_klonner.pdf

[26]Komito, Lee (2011). Social Media and Migration: Virtual Community 2.0. Journal of the American Society for Information Science and Technology 62(6), 1075-1086.

[27] Li, Wei, and Lixin Colin Xu (2004). The Impact of Privatization and Competition in the Telecommunications Sector around the World. Journal of Law and Economics 47(2), 395-430.

[28]Lin, Justin Yifu (1992). Rural Reform and Agricultural Growth in China. American Economic Review, 82, 34-51

[29]McKenzie, David, and Hillel Rapoport (2010). Self-selection Patterns in Mexico-US migration: The Role of Migration Networks. The Review of Economics and Statistics 92(4), 811-821.

[30]McKenzie, David \& Gibson, John \& Stillman, Steven (2013). A land of Milk and Honey with Streets Paved with Gold: Do Emigrants Have Over-optimistic Expectations about Incomes Abroad?. Journal of Development Economics 102, 116-127.

[31]Meng, Xin (2000). Labor market reform in China, Cambridge: Cambridge University Press.

[32]Meng, Xin and Junsen, Zhang (2001). The Two-Tier Labor Market in Urban China: Occupational Segregation and Wage Differentials between Urban Residents and Rural Migrants in Shanghai. Journal of Comparative Economics 29(3), 485-504.

[33]Munshi, Kaivan (2003). Networks in the Modern Economy: Mexican Migrants in the U.S. Labor Market. Quarterly Journal of Economics 118, 549-597. 
[34]Muto, Megumi and Takashi Yamano (2009). The Impacts of Mobile Phone Coverage Expansion and Personal Networks on Migration: Evidence from Uganda. Word Development 37, 1887-1896.

[35]Muto, Megumi and Takashi Yamano (2011). Mobile Phone Coverage and Market Participation: The Case of Banana Marketing in Uganda. Emerging Development of Agriculture in East Africa, Springer Netherlands, 99-113.

[36]Naughton, Barry (2007). The Chinese Economy, Cambridge: MIT Press.

[37]Ngai, L. Rachel, and Christopher A. Pissarides (2007). Structural Change in a Multi-sector Model of Growth. American Economic Review 97(1), 429-443.

[38]Robinson, Sherman (1971). Sources of Growth in Less-Developed Countries: A Cross-Section Study. Quarterly Journal of Economics 85, 391-408.

[39] Solinger, Dorothy J. (1999). Citizenship Issues in China's Internal Migration: Comparisons with Germany and Japan. Political Science Quarterly 114(3), 455-478.

[40]Uhlig, Harald (2006). Regional Labor Markets, Network Externalities and Migration: The Case of German Reunification. The American Economic Review 96, 383-387.

[41]Wauschkuhn M (2001). Telecom and Economic Development in China. Berichte des Arbeitsbereichs Chinaforschung.

[42]Winters, Paul, Alain de Janvry, and Elisabeth Sadoulet (2001). Family and Community Networks in Mexico-U.S. Migration. Journal of Human Resources 36, 159-184.

[43]Wong, Christine (2012). Paying for urbanization in China: Challenges of Municipal Finance in the $21^{\text {st }}$ century. Prepared for R Rahl, J Linn, and D Wetzel, editors, Metropolitan Government Finance in Developing Countries. Cambridge, MA. Lincoln Institute for Land Policy.

[44]Wu, Irene S. (2008). From Iron Fist to Invisible Hand: The Uneven Path of Telecommunications Reform in China, Stanford, CA: Stanford University Press.

[45]Wu, Harry Xiaoying (1994). Rural to Urban Migration in the People's Republic of China. China Quarterly 139, 669-698. 
[46] Yamauchi, Futoshi, and Sakiko Tanabe (2008). Nonmarket Networks among Migrants: Evidence from Metropolitan Bangkok, Thailand. Journal of Population Economics 21(3), 649-664.

[47]Zhao, Yaohui (1999). Leaving the Countryside: Rural to Urban Migration Decisions in China. American Economic Review 89, 281-286.

[48]Zhao, Yaohui (2000). Rural to Urban Labor Migration in China: The Past and the Present, in Rural Labor Flows in China, eds. Institute of East Asian Studies, University of California, Berkeley.

[49]Zhao, Yaohui (2003). The Role of Migrant Networks in Labour Migration: The Case of China. Contemporary Economic Policy, 21, 500-511.

[50] Zhao, Zhong (2004). Rural-Urban Migration in China-What Do We Know and What Do We Need to Know?. China Economic Quarterly, 3, 517-536. 